\title{
Título: Olhares da margem: estudos de gênero nas letras uspianas
}

\author{
AUTORAS: Natalia de Oliveira Ribeiro C. Gomes* e Viviane Araújo Alves da Costa Pereira**
}

Será que a USP, universidade pioneira no Brasil em diversos aspectos, inclusive no que diz respeito ao próprio sentido de congregar os estudos científicos, já atentou para algo como a diversidade? É difícil falar de maneira tão global em termos de "universidade", já que esta se constrói a partir de institutos e faculdades obviamente distintos; o que se deseja buscar, na realidade, tem a ver especificamente com os estudos na área de Literatura. Assim, o objeto que nos propusemos foi a pesquisa em literatura que tematizasse o gênero como recorte determinante. A diversidade que buscamos neste espaço de reflexão acolhe literatura feminina, crítica feminista, teoria queer, estudos da homocultura; enfim, pesquisas que valorizem as identidades sexuais e as relações do corpo dentro do universo literário. As relações entre gênero e literatura parecem ter um espaço mais aberto para a discussão em outras universidades, como a Universidade de Brasília - UnB, a Federal e a Estadual da Paraíba - UFPB e UEPB, a Universidade Federal de Minas Gerais - UFMC, a Universidade Federal de Santa Catarina - UFSC, a Unicamp; o que acontece com a USP?

A ambição da proposta é grande diante das expectativas que se delineiam a partir de certas premissas da realidade uspiana. Explico-me: com correntes teóricas bastante determinadas e a contínua valorização dos clássicos, com a primazia do texto, os estudos de literatura da USP não me parecem, de antemão, um cenário propício para o desenvolvimento de pesquisas que tocam temas menos estritamente acadêmicos, advindos de uma literatura relativamente recente $e$, ainda, marginal. Não que as relações com o corpo e as individualidades sexuais sejam assunto novo ou "da moda": Safo, poetisa da ilha de Lesbos que viveu no século VII a.C. está aqui, com todos os derivados de seu nome e de sua terra, para nos provar o contrário. No entanto, os estudos feministas e de teoria queer ecoam um interesse crescente, sobretudo a partir dos anos 70 do século XX, com obras que cada vez mais se libertam de conceitos restritivos sobre o que cabe na literatura e começam a abarcar uma relação que envolve o corpo e suas experiências.

$\mathrm{Na}$ apresentação do curso Sexualidade e Ciências Sociais, no prédio vizinho ao de Letras, onde a matéria é oferecida todos os semestres pelo departamento de Antropologia, o professor Júlio Simões relatou pontos de sua trajetória como pesquisador da sexualidade e da homocultura no campo antropológico. Seu relato mais interessante, no entanto, foi contado de maneira anedótica: ao entrar no Mestrado da Unicamp, nos anos 80, seu futuro orientador desaconselhou uma pesquisa dentro do campo das sexualidades - afirmando que se tão cedo em sua carreira adentrasse no tema, ficaria marcado por seus pares como "o especialista em viadologia", colocando para si mesmo inúmeros obstáculos. Os risos ecoaram na sala de aula; a piada cumpre sua função. A aparente distância temporal e espacial do relato e o fato do professor ser hoje um dos grandes nomes dos estudos de gênero no Brasil, permitem o riso desse episódio.

\footnotetext{
* Graduanda em Letras na Universidade de São Paulo. Realiza pesquisa de Iniciação Científica com fomento do CNPq analisando autobiografias femininas pelo viés dos estudos de gênero. Contato: nanadeluca.oliveira@gmail.com

** Doutoranda do programa de pós-graduaçao em Estudos Linguísticos, literários e tradutológicos do Francês. Bolsista CNPQ. Membro do grupo de pesquisa Criação e Crítica. Contato: vaacpereira@yahoo.fr
} 
Das dificuldades que visualizo desde o primeiro momento, talvez a mais importante seja a de que os estudos de gênero estão necessariamente inseridos em um tipo de abordagem trans/multi/ interdisciplinar. Assim, a proposta de isolar o cantinho da literatura, por si, já limita muito o campo a percorrer. Excluindo os filtros "sociologia" e "antropologia", a pesquisa nos revela sobretudo textos que tangenciam, sem adentrar, os estudos de gênero; há uma enxurrada de trabalhos que tematizam a construção da personagem feminina no romance $X$ ou os episódios homoeróticos do romance $Y$, sem que isso se configure como um estudo efetivo de gênero, mas antes, dentro da teoria literária, estudo da composição e de elementos estruturantes da obra romanesca.

Nossa pesquisa, no entanto, mostra que este aparente abismo pode talvez ter diminuído no campo das Ciências Sociais, mas em Letras nada nos leva a crer que o conselho dado à Júlio Simões tenha expirado. Ao realizar nosso levantamento, fica clara a desconexão quase diaspórica entre os pesquisadores que se prestam aos estudos feministas e de gênero na Letras-USP. Estamos espalhados por diversas áreas da faculdade (Portuguesa, Brasileira, Africanas, Hebraico, Árabe, Inglês, Francês, Alemão, Teoria Literária) sendo que raramente nos encontramos - no sentido de que quase nada é organizado na faculdade em função de fazer convergir estes diferentes estudos. Mais interessante ainda foi descobrir que os professores que trabalham nesta área de estudos orientam poucos ou nenhum trabalho no tema; de maneira que a maioria dos pesquisadores de graduação e pós-graduação estão sob tutela de professores doutores de campos completamente distintos. Ou seja, não existe uma tradição do conhecimento nem de sua transmissão quando se trata dos Estudos de Gênero e Feministas no curso de Letras da USP, preceitos básicos para que se forme um campo de estudo verdadeiro, acessível a todas as gerações de estudantes e professores. Indagamos-nos, então, a respeito dos porquês.

No cânone da literatura a que se aplicam os estudos de gênero, Clarice Lispector é presença obrigatória; e quase exclusiva, na verdade. Quando se pensa em literatura de autoria feminina no Brasil, o principal nome é certamente o de Clarice, do que é testemunha a produção volumosa e muito valiosa da professora Nádia Gotlib: no levantamento empreendido, chama a atenção o projeto contínuo de pesquisa acerca da obra da autora, que começa a ser realizado por seus orientandos na década de 90 e se estende até hoje. Mas não se pode ignorar, é claro, outros nomes importantes de escritoras da literatura brasileira, como Cecília Meirelles, Adélia Prado e Hilda Hilst que, embora não gozem do relevo dado a Clarice, também são assunto de estudos significativos. Pode-se pensar, nesse sentido, que a presença das mulheres no campo dos estudos acadêmicos é metonímia de fenômeno maior, que reserva à mulher um espaço bem pequeno dentro do cânone literário, dominado por escritores e, assim, o que se vê nas pesquisas é, em alguma medida, extensão da pouca ênfase dada à literatura feminina.

Vale, pois, antes de revelar os resultados das buscas por corpos que dialoguem com outros corpus, retomar o que se entende aqui por estudos de gênero. Realizamos nossa pesquisa procurando delimitar a produção científica dos últimos dez anos de dissertações e teses (e também trabalhos de iniciação científica) realizadas em literatura na USP que não apenas tematizassem o feminino ou o homossexual, mas que objetivassem as relações de gênero como constituintes nas obras escolhidas. Em primeiro momento, acessamos a página virtual da FFLCH e, de departamento em departamento, buscamos docentes que se situassem como estudiosos desta área, ou, pelo menos, se aproximassem dela, encontrando onze docentes a partir deste critério. $\bigcirc$ Departamento de Letras Clássicas e Vernáculas concentra o maior índice, com oito dos onze docentes (o que não é surpreendente, tendo em vista que o DLCV agrega o maior número de áreas da faculdade); temos mais uma docente do Departamento de Teoria Literária e Literatura Comparada e duas do 
Departamento de Letras Modernas (Inglês e Alemão) ${ }^{* 1}$. Depois efetuamos uma busca no Dedalus (sistema integrado de bibliotecas da Universidade de São Paulo), onde buscamos trabalhos a partir das palavras-chave "estudos de gênero", "mulheres", "homoerotismo" e "sexualidade", restringindo nossa busca à Faculdade de Filosofia, Letras e Ciências Humanas.

Logo fica clara a falta de centralização dos estudos de gênero na Universidade de São Paulo. E os reflexos disto na faculdade de Letras não estão somente no fato de que os pesquisadores estão dispersos em suas áreas, mas um outro dado que também nos ficou aparente:

Dos resultados encontrados, procuramos selecionar as teses e dissertações que dialogassem diretamente com a teoria e a crítica feminista e de gênero. Dentre os trabalhos levantados para esta breve revisão da produção acadêmica em Literatura na USP, devo ressaltar que mesmo nos trabalhos centrados na produção de mulheres o foco do estudo tende a ser outro, como a análise psicanalítica de obras de Clarice (e vale citar aqui a importante contribuição da professora Yudith Rosenbaum) ou a comparação de contextos sociais entre escritoras brasileiras e africanas. Exemplar dessa recusa em abordar a escrita pelo viés feminista, o trabalho de Michela Rosa Di Candia, que tematiza a mutilação genital feminina na produção de Alice Walker, explicita no resumo que "é pressuposto que o olhar da protagonista é o produto da soma de todas as escolhas feitas pelo autor-implícito que, ao optar pela utilização das múltiplas vozes na composição do romance, denuncia as consequências físicas e psicológicas resultantes da submissão ao ritual da circuncisão e assume um posicionamento controverso". O tema, tão marcadamente feminino, na medida em que trata de um corpo e de uma identidade que só podem pertencer à mulher, acaba "psicanalisado" por uma abordagem que prima por um aspecto de construção da narrativa: o discurso do autor-implícito. A tese não perde sua representatividade para os estudos de gênero, na medida em que traz à discussão uma obra absolutamente significativa para se pensar a questão da mulher; no entanto, parece-me que a necessidade de conferir cientificidade à pesquisa acaba por desviar o que poderia ser o foco central da discussão.

Será que as escolhas de como ler determinada obra são realmente escolhas? Ou tratar-se-ia antes da falta de interlocutores e, mais amplamente, de um grupo maior que congregue as pesquisas de estudos de gênero?

Em rápida pesquisa sobre universidades que são referência e polos firmados para os estudos de gênero, como a Unicamp e a UFSC, encontramos o Instituto Pagu e o Instituto de Estudos de Gênero (IEG) respectivamente, institucionalizados em ambas as universidades ${ }^{* 2}$. Apresentam objetivos concretos e similares: a centralização dos estudos de gênero em suas universidades de origem e a agregação destes estudos oriundos de diferentes campos de conhecimento. Assim, são institutos interdisciplinares, onde atuam professores de diversas áreas de conhecimento. Os projetos vão desde pesquisas até atuações conjuntas com os movimentos sociais relacionados aos direitos da mulher e da igualdade de gênero. O IEG não é uma iniciativa tão somente da UFSC, mas agrega professores e projetos de outras três universidades de Santa Catarina, dividido ele próprio em diversos Núcleos e Laboratórios de pesquisa, que vão desde os estudos sobre gênero e cultura à agricultura familiar. Ambos os Institutos possuem publicações feministas e de gênero, como os Cadernos Pagu, publicação impressa semestral que reúne artigos de diversas áreas de conhecimento dentro do campo de estudos feministas; e a própria Revista de Estudos Feministas,

\footnotetext{
* 1 Do DLCV, os professores Emerson da Cruz Inácio, Jaime Ginzburg, José Horácio do Nascimento Costa, Mário César Lugarinho, Marlise Vaz Bridi, Nádia Batella Gotlib, Simone Caputo Gomes e Yudith Rosenbaum. Do DTLLC, a professora Regina Pontieri. Do DLM, as professoras Laura Patrícia de Zuntini Izarra (Inglês) e Eva Maria Clenk (Alemão).

*2 Instituto de Estudos de Gênero - http://www.ieg.ufsc.br e Instituto Pagu - http://www.pagu.unicamp.br/
} 
publicação quadrimestral, cujo objetivo é apresentar reflexões contemporâneas e inovadoras dos estudos da mulher e de gênero. E na USP? Encontramos o Núcleo de Estudos da Mulher e Relações Sociais de Gênero, cadastrado como um Núcleo da Faculdade de Filosofia, Letras e Ciências Humanas, onde só atuam, contudo, docentes e alunos da Faculdade de Geografia. De acordo com seu site (http://nemge.wordpress.com) possui oito pesquisas e teses publicadas.

Na faculdade de Letras, o programa Estudos Comparados de Literaturas de Língua Portuguesa parece concentrar parte significativa dos estudos de gênero ligados à literatura dentro da Universidade de São Paulo. Os professores Mário César Lugarinho, Emerson da Cruz Inácio e José Horácio Costa, com participação efetiva na ABEH, Associação Brasileira de Estudos da Homocultura, e também pela recente criação do grupo de pesquisa "Literatura e diversidade sexual" (cadastrado no site do CNPQ em 2010) testemunham, ao mesmo tempo, o engajamento dos professores (e seus orientandos) na discussão política e artística dos temas da diversidade, e o isolamento que os circunscreve, tendo pouco diálogo dentro da instituição e estabelecendo, necessariamente, outros diálogos, com outros centros acadêmicos. Interessante - e mais que isso, revelador - pensar que, embora vinculados aos estudos de gênero, com linhas de pesquisa como "literatura e teoria queer" e "literatura e homocultura", as pesquisas sob sua orientação não se vinculam apenas ao que é realizado pelo grupo de pesquisa, mas, por outro lado e com maior ênfase, demonstram ligação com o departamento que integram. Nesse sentido, considero um dado bastante significativo o fato de o professor Mário Lugarinho ter orientado mais pesquisas que tratam de homocultura na época em que era professor da Universidade Federal Fluminense, sendo que seus orientandos da USP trabalham outras questões relativas à identidade do homem contemporâneo. Do programa de Estudos Comparados, além dos professores citados, temos ainda, sobretudo nos estudos de autoria feminina realizados na USP a partir de 2000, a presença da orientação das professoras Benilde Justo Lacorte Caniato (falecida), Marlise Vaz Bridi e Simone Caputo Comes, com a supervisão de pesquisas acerca das marcas do feminino em literaturas do Brasil, Portugal e de países africanos de Língua Portuguesa. De maneira particular, a professora Simone Caputo Comes, com vários orientandos em todos os níveis (de iniciação científica a pós-doutorado) dedicados ao estudo da escrita de autoria feminina, parece responder atualmente com mais ênfase pela produção acadêmica dos estudos de autoria feminina na USP, fato reiterado também pela linha de pesquisa "Escritura literária de autoria feminina" que integra o grupo de pesquisa por ela coordenado: "Estudos cabo-verdianos: literatura e cultura", cadastrado no site do CNPQ.

Por que será que a maior parte dos estudos feministas e de gênero estão locados nos Estudos comparados de literaturas de língua portuguesa? Arriscaria dizer que os estudos de gênero dialogam mais de perto com os Estudos Culturais do que com a teoria da literatura mais tradicional ou a crítica de vertente sociológica, e a produção dos países ex-colônias de Portugal - Brasil e África lusa -, por sua condição de explorados e retardatários em relação à própria produção artística, quando comparados aos europeus, são terreno fértil para investigações que tratam de minorias intelectuais. Assim, não espanta o fato de que os Estudos Comparados de Literaturas de Língua Portuguesa, mais abertos às novas tendências pela própria condição de lidar com uma literatura bastante recente e que demanda outros instrumentos de leitura, ofereçam grande parte dos estudos em literatura feminista e/ou de gênero.

Toda escolha por um escopo de pesquisa perpassa uma ideologia; mesmo a escolha aberta por uma não-ideologia, por si só, já desponta em um posicionamento ideológico. No caso de uma pesquisa feminista e de gênero, este posicionamento torna-se mais evidente, e a escolha por este recorte não permite uma relação diferente entre pesquisador e pesquisa. Há uma valoração e 
hierarquização dos gêneros em nossa sociedade e, a partir do momento que um pesquisador opta por prestar atenção nesta hierarquização e nos gêneros oprimidos, a ideologia é transparente.

Da quase interdependência entre opressão e estudos de gênero, interessa notar ainda um dado revelador: de 40 dissertações/teses identificadas segundo nossos critérios, 4 focalizam a mulher ou o homossexual dentro de um contexto religioso específico: o judaísmo ou o islamismo; outras 4 enfatizam a combinação dos fatores "mulher" e "etnia/cor" como determinante da produção poética de escritoras; nas demais, não é raro encontrar expressões que apontam para o caráter de afirmação identitária dessa escrita: "feminino transgressor" (Jane Pinheiro de Freitas), "solidão e resistência" (Heloísa Corrêa Moura), "julgamento" (Jorge Luís de Teixeira), "identidade, memória e gênero" (Suely Alves de Carlos) etc.

Procurando verificar se os pesquisadores que defenderam dissertações e teses que dialogassem com a proposta deram continuidade aos estudos na área, fomos buscá-los na Plataforma Lattes do CNPQ: descobrimos, não sem interesse, que vários dentre eles acabaram por continuar, sim, suas pesquisas de gênero, mas em outras áreas. Assim, Eliezer Serra Braga, que desenvolveu dissertação sobre o papel da mulher na Bíblia, sob orientação de Ruth Leftel, continua a estudar as relações entre mulher e religião, mas agora dentro do programa de História da UNESP de Assis. Francisco Maciel Silveira Filho, que trabalhou especificamente com a questão da identidadel diversidade sexual em Santareno durante o mestrado, acabou, no doutorado, migrando para a Psicologia. Marina Juliana Oliveira Soares estuda as relações da mulher na cultura árabe, mas agora na História Social, e não mais ligada à área de Língua e Literatura Árabe. Daí se pode retomar a questão dos estudos de gênero sob uma ótica transdisciplinar: não adiantou excluir, a priori, a sociologia e a antropologia de nossas buscas, já que esses outros campos voltam, juntamente com a história e a psicologia, nos devires das pesquisas que se realizam sobre gêneros.

Uma dúvida bastante séria me assalta durante a pesquisa: será que levantamos dados suficientes para traçar hipóteses acerca da (ausência de) produção acadêmica que se inscreve no campo de estudos de gênero? Certamente, o inventário não é exaustivo, uma vez que tivemos acesso apenas ao que está de alguma maneira publicado, seja na base de dados das bibliotecas da USP, seja por meio da Plataforma Lattes - o que exclui, por exemplo, projetos de pesquisa em Iniciação Científica que, ainda incipientes ou realizados sem financiamento, não têm um registro formal.

A fundadora do Coletivo de Mulheres da Letras e militante da Marcha Mundial de Mulheres, Ana Araújo, respondeu de maneira à primeira vista contraditória a minha pergunta objetiva "Você faz pesquisa?": faço, mas por conta própria, não tenho vínculo com a Letras. Sua pesquisa parte de um fato conhecido - o lugar de escrita e do fazer literário da mulher é, por excelência, o espaço privado, sendo o público reservado ao homem; a partir disso, Ana analisa a obra poética de Ana Cristina César averiguando os desdobramentos deste lugar de desconforto desenhando "o percurso da escrita feminina, sua posição de desconforto e os reflexos causados em sua própria prática literária". Assim, surge meu estranhamento - por que alguém tão obviamente comprometida com as questões de gênero em nossa sociedade realiza sua pesquisa de maneira autônoma e independente da instituição em que se encontra? Por que esta pesquisa não está sendo orientada por nenhum professor e não possui o convencional vínculo acadêmico? A resposta de Ana Araújo me pareceu ainda mais relevante: "No fim das contas é porque nunca achei uma professora com a mesma linha de orientação ou que me empolgasse de decidir que ia querer que ela me orientasse, porque uma linha mais marxista dificilmente chega a uma linha feminista marxista. (...) Tenho interesse em pesquisar isso, entrei na Letras somente por isso e continuo somente por isso. Mas não encontro uma professora que eu ache que tenha concordâncias mínimas - politicamente - comigo. E daí 
não me sinto motivada.". A reposta de Ana Araújo não contradiz em absoluto o que observamos em nosso levantamento - a ausência de uma estrutura em nossa faculdade que permita que os estudos feministas e de gênero se organizem e constituam uma unidade coesa leva, também, à ausência de motivação e à dificuldade de encontrar uma orientação acadêmica; não há, de fato, um início de trajetória evidente para estes estudos. Convencionalmente, encontramos nossos futuros orientadores e temas possíveis de pesquisa nas salas de aula - os estágios embrionários de uma pesquisa de iniciação científica se dão na relação da tríade professor-tema do curso-aluno. Em alguns casos, o aluno possui uma motivação pessoal para o tema $x$ ou y e procura os professores que atuam dentro de sua área de interesse, buscando a afinidade entre o tema da pesquisa em potencial e a produção acadêmica do professor escolhido. Mas há uma grande dificuldade em encontrar o início desta vereda quando a área pretendida é a feminista e de gênero; não há um curso específico que se possa frequentar para ter contato com esta área. De fato, eu, pessoalmente, tive que migrar parcialmente para o prédio de Ciências Sociais de forma a poder ter contato em sala de aula com o tema de minha pesquisa.

Volto, então, às buscas, com nova palavra-chave: “lésbica”, que pode funcionar como chave tanto nos estudos feministas quanto de gênero; resultado: um trabalho de iniciação científica, "O discurso da literatura lésbica no final do século XX no Brasil”, realizado por Débora Cristina Ferreira de Camargo sob orientação do professor Antônio Vicente Pietroforte (que orientou, também por meio da abordagem semiótica, a pesquisa de Jorge Luís Teixeira sobre Nossa Senhora das Flores, de Jean Genet, um ícone da literatura gay). E só. Apenas um resultado.

Parece haver certa recusa pela nomenclatura que particulariza os estudos feministas e de gênero, e o que procuramos identificar era justamente um tipo de abordagem "assumida", que declarasse o interesse particular pela relação entre gênero e literatura. Nesse sentido, as novas investidas nas bases de dados, ao invés de trazer à tona mais trabalhos na área, acabaram por excluir alguns, que, embora o tocassem, não passavam pelo estreito filtro - a contrainte que nos propusemos - chamado "literatura": os trabalhos de Lajosy Silva e Roberto Rillo Bíscaro, ambos orientados pela professora Maria Silvia Betti, assumiam entre os assuntos (ou palavras-chave) a expressão "teatro gay”, ao tratar respectivamente de peças dos dramaturgos norte-americanos contemporâneos Martin Sherman e Brad Fraser, mas se encontram vinculados ao Departamento de Artes Cênicas da ECA.

Temos receio do caráter de denúncia que este texto pode assumir. Em alguma medida, sim, trata-se de denunciar a falta de espaço para o diálogo, em nível acadêmico, a respeito dos estudos de gênero, que continuam marginais nas nossas Letras; denunciar a fragmentação que silencia o pesquisador, ou o faz buscar outros ares, na sociologia ou na psicologia; denunciar a necessidade de afirmação identitária - a exemplo do que ocorre na literatura ficcional - do estudioso que se dedica à leitura dessa mesma literatura: de maneira análoga à reivindicação de uma voz particular, seja a voz feminina de Clarice, seja a voz gay de Genet, também precisa de voz quem se dedica aos estudos feministas e de gênero. Assim, mais do que um simples objetivo de denúncia, o que motivou o levantamento realizado é o desejo de saber que, apesar de serem raras, as pesquisas sobre gêneros em Literatura existem na Universidade de São Paulo; que há mais estudantes e professores dedicados a tratar da diversidade tanto em romances, poemas, peças de teatro quanto em obras de teoria queer e crítica feminista. Assim, convidamos ofendidos e assumidos a ampliar nosso inventário, trazendo colaborações de outros trabalhos de pesquisa que, realizados ou em andamento, participem dessa conversa.

Em tempo: poucos dias antes do fechamento da presente edição da revista Criação e crítica, recebemos um e-mail encaminhado pelo Departamento de Letras Modernas com a divulgação 
do simpósio "Literatura e Homocultura", organizado pelos professores Emerson da Cruz Inácio (USP) e Jorge Valentim (UFSCAR), a ser realizado no II Cielli, em Maringá/PR, o que nos parece uma primeira resposta ao convite para o diálogo.

\section{REFERÉNCIAS BIBLIOGRÁFICAS}

\section{Dissertações e Teses disponiveis na Biblioteca Florestan Fernandes:}

ALMEIDA, Joel Rosa de. Onde estivestes de noite: a experimentação do grotesco. Orient.

Regina L. Pontieri. São Paulo: USP, 2001.

BATISTA, Elisabeth. Entre o mito e o preconceito: a figura da mulher na condição de sogra sob os olhares de Fialho de Almeida em A velha e Aluísio Azevedo em Livro de uma sogra. Orient. Benilde Justo Lacorte Caniato. São Paulo: USP, 2002.

BRACA, Eliézer Serra. Santas e sedutoras: as heroínas na Bíblia hebraica - a mulher entre as narrativas bíblicas e a literatura patrística. Orient. Ruth Leftel. São Paulo: USP, 2008.

CAMPOS, Maria Elvira Brito. Viver com os outros e reunião de família: encontros e desencontros. Orient. Benilde Justo Lacorte Caniato. São Paulo: USP, 2003.

CARDOSO, Beatriz Amazonas. Eu sou mulher e não tenho a pena de Homero: Theresa

Margarida da Silva e Orta e as origens da escritura feminina portuguesa. Orient. José Horácio Costa. São Paulo: USP, 2009.

CARLOS, Suely Alves de. Identidade, memória e gênero nas obras literárias de Orlanda Amarílis e Clarice Lispector. Orient. Simone Caputo. São Paulo: USP, 2009.

CORRÊA, Cláudia Maria Fernandes. Ecos da solidão: uma autobiografia de Maya Angelou.

Orient. Lynn Mário Trindade Menezes de Souza. São Paulo: USP, 2009.

CORREIA, Márcio Antonino Lourenço. Estranhamento, desencontro e solidão: a representação da família na ficção de Carlos de Oliveira. Orient. Marlise Vaz Bridi. São Paulo: USP, 2009.

DE SÁ, Sheila Pelegri. Eros de Lilith: um olhar para a construção da feminilidade em romances portuguesas pós-revolução. Orient. Marlise Vaz Bridi. São Paulo: USP, 2009.

DI CANDIA, Michela Rosa. As implicações da mutilação genital feminina na constituição do sujeito em Possessing the secreto of Joy, de Alice Walker. Orient. Laura Patrícia Zuntini de Izarra. São Paulo: USP, 2003.

. Signifyin(g) womanhood: the short fiction of Zora Neale Hurston and

Alice Walker. Orient. Laura Patrícia Zintini de Izarra. São Paulo: USP, 2008.

FARIA, Milena de Oliveira. Quando as mulheres estão no poder: ambiguidades, obscuridades e referências políticas em As Tesmoforiantes de Aristófanes. Orient. Adriane da Silva Duarte. São Paulo: USP, 2010.

FICUEIREDO, Roseana Nunes Baracat de Souza. Luísa e Capitu: faces femininas do século XIX. Orient. Benilde Justo Lacorte Caniato. São Paulo: USP, 2001.

FREITAS, Jane Pinheiro. Visões do (des)encanto: um estudo sobre o feminino transgressor em Clarice Lispector e Maria Judite de Carvalho. Orient. Maria dos Prazeres Santos Mendes. São Paulo: USP, 2011.

GENTA, Alda Maria Arrivabene. A gata e a fábula e exílio: a manifestação do desamor no mundo moderno. Orient. Benilde Justo Lacorte Caniato. São Paulo: USP, 2005.

GLASMAN, Jane Bichmacher de. De Rachel a Rachel: mulher, amor e morte. Orient. Nancy

Rozenchan. São Paulo: USP, 2001.

MACHADO, Alleid Ribeiro. As personagens femininas de Júlia Nery: paradigmas e

representações. Orient. Flávia Corradin. São Paulo: USP, 2011. 
MAFRA, Telma Aparecida. O silêncio e a palavra truncada nos contos de Maria Judite de Carvalho. Orient. Marlise Vaz Bridi. São Paulo: USP, 2002.

. Marias e Marianas: relatos de coragem. Orient. Marlise Vaz Bridi.

São Paulo: USP, 2007.

MONTALVÃO, Sérgio Aguiar. A homossexualidade na Bíblia hebraica: um estudo sobre a prostituição sagrada no Oriente Médio. Orient. Moacir Amâncio. São Paulo: USP, 2009. MOURA, Heloisa Corrêa. Clarice Lispector e Orlanda Amarílis: solidão e resistência. Orient. Nádia B. Gotlib. São Paulo: USP, 2001.

OLIVEIRA, Niube Ruggero de. O olhar femino nas crônicas de Maria Judite de Carvalho e Clarice Lispector. Orient. Benilde Justo Lacorte Caniato. São Paulo: USP, 2000.

. Fios que se desfazem: a solidão em Clarice Lispector e Maria Judite de Carvalho. Orient. Benilde Justo Lacorte Caniato. São Paulo: USP, 2005. OLIVEIRA, Rosa de Souza. Olhares epifânicos: a epifania nos contos "Amor" de Clarice Lispector e "À sexta-feira” de Luandino Vieira. Orient. Benilde Justo Lacorte Caniato. São Paulo: USP, 2000.

. Da epifania à alteridade: Clarice Lispector e Luandino Vieira. Orient. Benilde Justo Lacorte Caniato. São Paulo: USP, 2006.

PEREIRA, Érica Antunes. De missangas e catanas: a construção social do sujeito feminino em poemas angolanos, cabo-0verdianos, moçambicanos e são-tomenses (análise de obras de Alda Espírito Santo, Alda lara, Conceição Lima, Noémia de Sousa, Paula tavares e Vera Duarte). Orient. Tânia Celestino de Macêdo. São Paulo: USP, 2010.

PUZZO, Miriam Bauab. A condição feminina na literatura brasileira: Cecília Meireles e Adélia Prado. Orient. Nádia B. Gotlib. São Paulo: USP, 1997.

O problemático não-lugar do fazer poético de Cecília Meireles. Orient. Maria Augusta Bernardes Fonseca. São Paulo: USP, 2004.

QUEIROZ, Sônia Maria Alves de. Literatura e Representação Social das Mulheres em Cabo Verde: Vencendo Barreiras. Orient. Simone Caputo Gomes. São Paulo: USP, 2010. REZENDE, Jussara Neves. Charneca em flor e meu glorioso pecado: nos domínios de Eros. Orient. Benilde Justo Lacorte Caniato. São Paulo: USP, 2001. . A simbolização nas imagens Cronotopos poéticos em Cecília Meireles

e Sophia de Mello Breyner Andresen: tempo e espaço. Orient. Benilde Justo Lacorte Caniato. São Paulo: USP, 2006.

RODRICUES, Jussara Oliveira. Cabo Verde em perspectiva feminina: a produção literária em língua portuguesa de Ivone Aída Ramos e Orlanda Amarílis. Orient. Simone Caputo Gomes. São Paulo: USP, 2012.

RUIZ, Betina dos Santos. Matrizes para um estudo da literatura feminina: uma leitura comparativa de Sóror Mariana Alcoforado e Sor Juana Inés de la Cruz. Orient. Horácio Costa. São Paulo: USP, 2010.

SANTOS, Elaine Cuencas. Mulheres e literatura na revista A mensageira. Orient. Nádia Batella Gotlib. São Paulo: USP, 2000.

SÃO JOÃO, Mariângela Dassi. Vozes femininas: ponto e contraponto - análise das obras Paisagem sem barcos, de Maria Judite de Carvalho, e Antes que o amor acabe, de Patrícia Bins. Orient. Benilde Justo Lacorte Caniato. São Paulo: USP, 2004.

SILVEIRA FILHO, Francisco Maciel. Cativeiros de papel: o verso, o reverso e o transverso do ser diverso em Santareno. Orient. Flávia Corradin. São Paulo: USP, 2008. 
SOARES, Marina Juliana de Oliveira. Erótica sem véu: o corpóreo sexual na sociedade árabeislâmica clássica (século XII). Orient. Mamede Mustafa Jarouche. São Paulo: USP, 2009. SOUZA, Mailza Rodrigues Toledo. Do corpo ao texto: a mulher inscrita/escrita na poesia de Hilda Hilst e Ana Paula Tavares. Orient. Benjamin Abdala Jr. São Paulo: USP, 2009. TEIXEIRA, Jorge Luís. O julgamento de Nossa Senhora das Flores, uma abordagem semiótica. Orient. Antônio Vicente Pietroforte. São Paulo: USP, 2004.

VENTURELLI, Paulo César. Um pequeno mundo flutuante. Literatura e homoerotismo em circuito fechado: Adolfo Caminha (O Bom-Crioulo) e Silviano Santiago (Stella Manhattan). Orient. Nádia Batella Gotlib. São Paulo: USP, 2001.

Iniciação Cientifica:

CAMARGO, Débora Cristina Ferreira de. $O$ discurso da literatura lésbica no final do século XX no Brasil. Orient. Antônio Vicente Pietroforte.

FERNANDES, Guilherme. Corpo e sexualidade em Caio Fernando Abreu. Orient. Jaime Ginzburg. CIROTO, Camila. Lavoura arcaica. Orient. Jaime Ginzburg.

GOMES, Natália de Oliveira Ribeiro C. Autobiografia feminina. Orient. Cláudia Amigo Pino. MIRANDA, Fernanda Rodrigues de. O sexo e a cor do poema: análise das obras poéticas de Paula Tavares, Conceição Evaristo e Conceição Lima. Orient. Mário Lugarinho (2009).

SALES, Sinei Ferreira. As identidades femininas representadas em Hilda Hilst, Adília Lopes e Judith / Epifania e homoerotismo: Uma leitura das obras de Paulo Teixeira e Valdo Motta. Orient. Emerson da Cruz Inácio.

SOUZA, Evelise Guioto de. Identidade e sexualidade da mulher negra vista por Alice Walker. Orient. Laura Patrícia Zuntini de Izarra. (2002)

\section{Pesguisas de pós-graduação em andamento (dados}

a partir da Plataforma Lattes do CNPQ):

Arnaldo Delgado Sobrinho. Chamamentos ao amigo: a reescrita da lírica amorosa nas poéticas de Hilda Hilst e Eugênio de Andrade. Orient. Emerson da Cruz Inácio.

Bruno César Martins Rodrigues. Caio Fernando Abreu e Al Berto: Marginalidade e Experiência do Corpo. Início: 2011. Orient. Emerson da Cruz Inácio.

Irinéia Lina Cesário. A ficção afro-negra de autoria feminina (provisório). Início: 2009. Orient. Simone Caputo Gomes.

Juliana Primi. Entre dois mundos: a loucura feminina em A Louca de Serrano, de Dina Salústio e O Alegre Canto da Perdiz, de Paulina Chiziane. Início: 2009. Orient. Simone Caputo Comes. Maurício Oliveira Rios. Percepções literárias em torno do gênero na sociedade cabo-verdiana: Dina Salústio, Germano Almeida e Evel Rocha. Início: 2008. Orient. Simone Caputo Gomes. Pedro Manoel Monteiro. Caminhos da ficção cabo-verdiana: Orlanda Amarílis e Fátima Bettencourt. Início: 2009. Orient. Simone Caputo Gomes.

Sinei Ferreira Sales. Hedonismo e masculinidades: poesia em Língua Portuguesa em perspectiva. Início: 2012. Orient. Emerson da Cruz Inácio. 